\title{
Early Ophthalmic Artery Blood Flow Parameter Changes in Patients with Type I Diabetes Mellitus
}

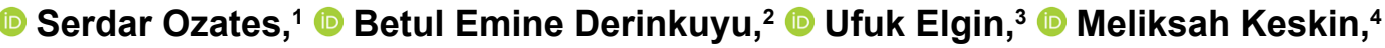 \\ (1) Nursel Muratoglu Sahin, ${ }^{4}$ (1) Zehra Aycan ${ }^{4}$ \\ 'Department of Ophthalmology, Kars Harakani State Hospital, Kars, Turkey \\ 2Department of Radiology, Dr. Sami Ulus Maternity, Children's Health and Diseases Training and Research Hospital, Ankara, Turkey \\ ${ }^{3}$ Department of Ophthalmology, Ulucanlar Eye Training and Research Hospital, Ankara, Turkey \\ ${ }^{4}$ Department of Endocrinology, Dr. Sami Ulus Maternity, Children's Health and Diseases Training and Research Hospital, Ankara, Turkey
}

\begin{abstract}
Objectives: The aim of this study was to assess initial changes in blood flow parameters of the ophthalmic artery (OA) in pediatric patients with type I diabetes mellitus (DM).

Methods: Sixty-three subjects were included in this prospective, cross-sectional, observational study. Thirty-one (49.2\%) patients with type I DM without diabetic retinopathy formed the DM group. The control group comprised 32 (50.8\%) healthy subjects. The OA of all of the patients was examined with Doppler ultrasonography. The main outcomes were peak systolic velocity (PSV), end diastolic velocity (EDV), pulsatility index (PI), and resistivity index (RI) measurements.

Results: The mean age at onset of type I DM was $10.7 \pm 2.0$ years and the mean duration was II.4 \pm II.0 months. The mean PSV and EDV outcomes in both eyes were significantly higher in the control group than in the DM group, whereas, the mean $\mathrm{PI}$ and $\mathrm{RI}$ outcomes in both eyes were significantly higher in the DM group $(p<0.05)$. A mean $\mathrm{RI}$ of $\geq 0.75$ indicated vascular hemodynamic changes associated with type I DM with a sensitivity of $72 \%$ and a specificity of $65 \%$ (area under the curve: $0.702 ; p=0.007$ ). A mean $\mathrm{PI}$ of $\geq 1.69$ predicted vascular hemodynamic changes associated with type I DM with a sensitivity of $79 \%$ and a specificity of $71 \%$ (area under the curve: $0.742 ; p=0.001$ ).

Conclusion: The results of this study revealed that disturbances in ocular hemodynamics might be present as early as the first year after a type I DM diagnosis. Changes in ocular hemodynamic parameters could be used to predict or screen for the development of vascular changes.

Keywords: Arterial resistance, blood flow, Doppler sonography, ophthalmic artery, type I diabetes mellitus
\end{abstract}

\section{Introduction}

Diabetes mellitus (DM) is a common systemic metabolic disorder; a significant proportion of the population across the globe suffers from long-term damage associated with DM, such as diabetic retinopathy (DR) $(I, 2)$. It has been reported that $83 \%$ of patients with type I DM develop some stage of DR within 10 years of DM onset (3). The period before
DR develops in patients varies; however, it has been found that retinal and vascular changes can occur even if no clinically significant $D R$ is present $(4,5)$. Vascular changes have an impact on ocular hemodynamics, and previous studies have documented how DM influences ocular hemodynamics (6-8). In the current body of literature, several studies have reported similar results for ocular hemodynamic changes, such as lower blood velocity and higher peripheric vascular

Address for correspondence: Serdar Ozates, MD. Kars Harakani Devlet Hastanesi, Goz Hastaliklari Anabilim Dali, Yenisehir Mahallesi, Ismail Aytemiz Blv. No: 55, 36200 Merkez, Kars, Turkey

Phone: +90 5377179110 E-mail: serdarozates@gmail.com

Submitted Date: November 04, 2019 Accepted Date: January 22, 2020 Available Online Date: February 14, 2020

${ }^{\circ}$ Copyright 2020 by Beyoglu Eye Training and Research Hospital - Available online at www.beyoglueye.com OPEN ACCESS This work is licensed under a Creative Commons Attribution-NonCommercial 4.0 International License. 
resistance, in patients with DR $(9,10)$, however, conflicting results have been described with regard to ocular hemodynamic changes before the development of clinically significant DR $(8, \mathrm{II})$.

DR is a consequence of microvascular disorder and altered insulin metabolism; it causes significant histopathological changes in the ocular vascular structure, such as endothelial changes, loss of pericytes, a narrowed vessel lumen, and a thickened basement membrane $(12,13)$. Therefore, it is not clear when the vascular structure and related ocular hemodynamic parameters begin to change. The objective of the present study was to investigate initial changes in ocular hemodynamics in pediatric patients with recently diagnosed type I DM without DR.

\section{Methods}

This prospective, cross-sectional, observational study was conducted at a tertiary referral hospital in accordance with the ethical standards of the Declaration of Helsinki. The study protocol was approved by the Ankara Kecioren Training and Research Hospital Clinical Research Ethics Committee in Ankara, Turkey (2012-KAEK-15/I664). All of the participants and their parents provided written, informed consent prior to undergoing any examination.

Patients aged between 5 and 21 years were included in the study, which was conducted between January 2018 and May 2018. Patients with retinal diseases, a history of retinopathy of prematurity, myopia or hyperopia greater than 3 diopters, uveitis, glaucoma, congenital cataract, or a history of ocular trauma were excluded. Patients using a vasodilator, vasoconstrictor, or inotropic drugs, and those with cardiovascular diseases, chromosomal anomalies, a history of vaso-occlusive diseases, or a history of metabolic diseases other than type I DM were also excluded. Patients with type I DM without DR were consecutively recruited and assigned to the DM group. Age-matched healthy participants without any ocular or systemic disease were consecutively recruited and assigned to the control group.

The type I DM diagnosis was confirmed by the endocrinology department of the hospital. Ophthalmological examinations were performed, including a best-corrected visual acuity test with a Snellen chart, non-contact tonometry, and a slit-lamp examination. One clinician (S.O.) performed the fundus examination of all of the patients. Fundus fluorescein angiography and optical coherence tomography were performed, if needed.

Doppler ultrasonography of the ophthalmic artery (OA) was performed using the Aplio 500 system (Canon Medical Systems Co, Ltd, Otawara, Japan) with a $10 \mathrm{MHz}$ linear transducer by a single radiologist (B.E.D.) to standardize the measurements. Doppler examination of the orbit was per- formed through the closed eyelid with the patient in the supine position. Care was taken to apply as little pressure as possible to the globe to avoid incorrect vascular recordings. The main arterial supply to the orbit is through the OA, which could be seen easily with color Doppler ultrasound by scanning medial to the optic nerve just $1.5 \mathrm{~cm}$ posterior to the globe. The main outcomes were peak systolic velocity (PSV), end diastolic velocity (EDV), pulsatility index (PI), and resistivity index $(\mathrm{RI})$ measurements. $\mathrm{RI}$ is an indicator of peripheral arterial resistance; it is calculated using the formula (PSV-EDV)/PSV. PI refers to the vascular impedance distal to the measurement site; it is calculated as (PSV-EDV)/mean velocity. The flow parameters of the OA were measured bilaterally 3 times and the mean was used as the outcome value.

Statistical analyses were performed with IBM SPSS Statistics for Windows, Version 22.0 (IBM Corp., Armonk, NY, USA). The assumption of normal distribution of data was assessed with the Kolmogorov-Smirnov test. Differences in descriptive data between groups were tested using a chisquare test. Differences in the outcomes between groups were tested with an independent samples t-test. The relationship between the outcomes was evaluated using Pearson's correlation. Receiver operating characteristic (ROC) curve analysis was performed, and the point that maximized Youden's index on the ROC curve was selected as the cutoff value. A level of $p<0.05$ was considered statistically significant for all tests.

\section{Results}

Thirty-two $(50.8 \%)$ healthy subjects [13 $(40.6 \%)$ males, 19 $(59.4 \%)$ females] were included in the control group and 3I (49.2\%) patients [I8 (58.1\%) males, I3 (4I.9\%) females] with type I DM were included in the DM group. Of the 31 patients in the DM group, 24 (77.4\%) were metabolically well-controlled and 7 (22.6\%) were not metabolically well-controlled. The mean age was $11.7 \pm 2.5$ years in the DM group and I2.8 \pm 2.8 years in the control group. Gender and mean age did not differ significantly between groups $(p=0.166, p=0.097$, respectively). In the DM group, the mean age at onset of type I DM was I0.7 \pm 2.0 years, and the mean duration of type I DM was II.4 I I .0 months.

Table I shows the mean Doppler sonography outcomes and a comparison of outcomes between the 2 groups. The mean PSV and EDV results in the right eye were significantly higher in the control group $(43.9 \pm 11.9 \mathrm{~cm} / \mathrm{seconds}, 1 \mathrm{I} .1 \pm 3.6$ $\mathrm{cm} / \mathrm{seconds}$, respectively) than in the DM group (37.6 \pm 9.2 $\mathrm{cm} / \mathrm{seconds}, 8.6 \pm 2.5 \mathrm{~cm} / \mathrm{seconds}$, respectively), while the mean $\mathrm{Pl}$ and $\mathrm{Rl}$ outcomes in the right eye were significantly higher in the DM group (I.82 $\pm 0.40,0.77 \pm 0.08$, respectively) than in the control group $(1.62 \pm 0.22,0.74 \pm 0.03$, respectively). The mean PSV and EDV outcomes in the left eye were sig- 


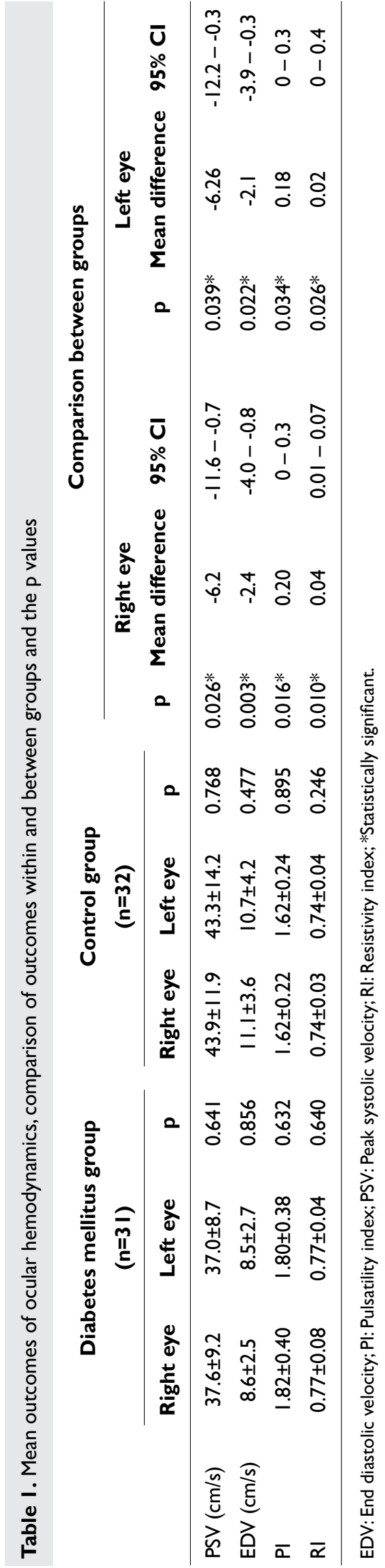

nificantly higher in the control group $(43.3 \pm 14.2 \mathrm{~cm} / \mathrm{seconds}$, $10.7 \pm 4.2 \mathrm{~cm} / \mathrm{seconds}$, respectively) than in the DM group $(37.0 \pm 8.7 \mathrm{~cm} /$ seconds, $8.5 \pm 2.7 \mathrm{~cm} /$ seconds, respectively), while the mean $\mathrm{PI}$ and $\mathrm{RI}$ outcomes in the left eye were significantly higher in the DM group $(1.80 \pm 0.38,0.77 \pm 0.04$, respectively) than in the control group $(1.62 \pm 0.24,0.74 \pm 0.04$, respectively). The mean outcomes of ocular hemodynamics did not differ significantly between the right eye and the left eye in either group. According to the ROC analysis, a mean $\mathrm{RI}$ of $\geq 0.75$ indicated vascular hemodynamic changes associated with type I DM with a sensitivity of $72 \%$ and a specificity of $65 \%$ (area under the curve $=0.702 ; p=0.007$ ). A mean $\mathrm{PI}$ of $\geq 1.69$ predicted vascular hemodynamic changes associated with type I DM with a sensitivity of $79 \%$ and specificity of $71 \%$ (area under the curve $=0.742 ; p=0.001$ ).

In the DM group, the mean glycated hemoglobin ( $\mathrm{HbAlc}$ ) level was $6.8 \pm 2.3 \%$ at the time of DM diagnosis and $5.9 \pm 1.1 \%$ at the time of examination with Doppler sonography. No correlation was found between the $\mathrm{HbAlc}$ level and ocular hemodynamic outcomes ( $p>0.05$ for each). The mean ocular hemodynamic outcomes were similar between patients with metabolically well-controlled DM and patients with metabolically uncontrolled DM. No correlation was found between the ocular hemodynamic outcomes and the duration and age of onset for type I DM ( $>>0.05$ for each).

\section{Discussion}

Our study revealed decreased blood velocity and increased $\mathrm{PI}$ in the OA of patients who had recently been diagnosed with type I DM. The combination of decreased blood velocity and increased $\mathrm{Pl}$ indicates increased vascular resistance. Similarly, Kawagishi et al. (9) reported that the PSV and EDV values were significantly lower and the RI was significantly higher in the central retinal artery of type I DM patients without retinopathy in comparison with healthy control subjects. Arai et al. (10) found that the RI of central retinal artery was significantly higher in DM patients without DR. Gil et al. (14) observed that there was an increase in OA resistance as the duration of DM increased. However, Ovali et al. (8) and Lockhart et al. (II) reported no change in the RI of the OA in patients with type I DM without DR. Many factors, such as age, race, duration of DM, glycemic control, site of measurement, and measurement technique, may affect ocular hemodynamics and lead to conflicting results (14-16). Although there is no consensus on changes in ocular hemodynamics before the development of DR, clear evidence has demonstrated that both micro- and macrovascular changes occur even if there is no clinical sign of DR (I7).

Our study showed that the RI was elevated in patients with type I DM. Increased vascular resistance is a consequence of changes in vascular structure. Thickening of the 
basement membrane, protein composition changes, and hyaline deposition are initial changes seen in the capillaries at the early stages of DM (12). Consistent with our findings, Romney et al. (4) noted that vascular compliance was reduced in both large and small arteries in type I DM before clinically apparent microvascular complications. Järvisalo et al. (17) and Pena et al. (18) found that the intima-to-media ratio thickness of the carotid artery was significantly higher in type I DM patients in comparison with healthy individuals. It is not clear whether microvascular changes trigger macrovascular changes, or if they progress simultaneously; however, it has been clearly established that the presence of DR predicts and increases the risk of macrovascular complications (I9-2I). Our study demonstrated altered hemodynamic changes in the $O A$ in the absence of clinically significant microvascular changes, including DR and nephropathy. Changes in the hemodynamic parameters of the OA could potentially be used to detect initial macrovascular changes in patients with type I DM. Supporting our suggestion, Ino-ue et al. (22) showed that increased PI could be used to predict macrovascular changes. Our study revealed that a mean RI of $\geq 0.75$ and a mean PI of $\geq 1.69$ predicted vascular hemodynamic changes associated with type I DM with a sensitivity of $72 \%$ and $79 \%$ and a specificity of $65 \%$ and $71 \%$, respectively. Arai et al. (I0) suggested that an $\mathrm{RI}$ of $\geq 0.80$ in the central retinal artery could distinguish patients with any stage of DR from healthy subjects with a sensitivity of $66 \%$ and a specificity of $88 \%$. Unlike some previous research, the present study highlighted the potential of Doppler sonography to predict vascular chances in the peripheral ocular vascular bed.

Previous epidemiological evidence has shown that proper glycemic control and lower $\mathrm{HbAIC}$ levels have a significant association with DR progression $(23,24)$. It has been suggested that intensive glycemic control be initiated as soon as possible after the onset of type I DM and that doing so is the best way to prevent DM complications $(23,25)$. Kawaguchi et al. (26) observed that higher plasma levels of glucose were associated with a higher RI in patients with type I DM and they suggested that intensive glycemic control decreased the RI. Although our patients received intensive treatment with the onset of type I DM and HbAIC levels decreased, changes in the ocular hemodynamic parameters occurred as early as at a mean of II months of DM duration. Vascular changes in DM have been attributed to several factors, including vascular endothelial growth factor (VEGF), insulin-like growth factor I (IGF-I), glycated proteins, free-radicals, and oxidized low density lipoprotein (LDL) $(4,5,18)$. The serum level of IGF-I has been found to begin to increase in the prepubertal period (27). IGF-I stimulates vascular smooth muscle proliferation; moreover, physiological elevations of the IGF-I level in puberty may trigger development of DR (28). The VEGF level was also found to be elevated in patients with DM with no microvascular changes in comparison with healthy subjects (5). High levels of IGF-I and VEGF may cause initial changes in the vascular structure prior to clinically significant complications. Furthermore, it has been speculated that insulin increases smooth muscle cell proliferation and the mass of extracellular matrix proteins, causing reduced vessel compliance $(4,28)$. Rodriguez-Fontal et al. (29) and Chantelau E. (30) reported that intensive glycemic control or acute reduction of hyperglycemia increased the risk of paradoxical worsening and the progression of DR in type I DM. Although there was no clinical sign of DR in the DM group, changes in the ocular hemodynamic parameters might be caused by tight glycemic control. However, histological and pathophysiological investigations are needed to provide evidence to support this suggestion.

There are several limitations to our study. HbAIC levels of all of the patients decreased after receiving intensive treatment; however, 7 patients had not yet reached the intended $\mathrm{HbAIC}$ level due to a short DM duration. Data obtained from those patients with metabolically uncontrolled DM may have caused bias and distorted our study results. DR was excluded based on a fundus examination without routinely using more objective methods, such as optical coherence tomography angiography, which could show microvascular changes before clinical presentation. In future studies, the exclusion of microvascular changes with optical coherence tomography angiography will improve the strength of the results.

Our results revealed that disturbances in ocular hemodynamics might be present as early as the first year after diagnosis of type I DM. Changes in ocular hemodynamic parameters could potentially be used to predict or screen for development of vascular changes; however, further longitudinal studies with more patients are needed to prove if this approach would be effective.

\section{Disclosures}

Ethics Committee Approval: The Ethics Committee of Ankara Kecioren Training and Research Hospital provided the ethics committee approval for this study (20I2-KAEK-I5/I664, 25.I.20I8).

Peer-review: Externally peer-reviewed.

Conflict of Interest: None declared.

Authorship Contributions: Involved in design and conduct of the study (SO, BED, UE); preparation and review of the study (SO, BED, UE, ZA); data collection (BED, MK, NMS, ZA); and statistical analysis (SO, BED, UE).

\section{References}

I. Chen L, Magliano DJ, Zimmet PZ. The worldwide epidemiology of type 2 diabetes mellitus-present and future perspectives. Nat 
Rev Endocrinol 201 I;8:228-36. [CrossRef]

2. American Diabetes Association. Diagnosis and classification of diabetes mellitus. Diabetes care 2014;37:8I-90. [CrossRef]

3. Klein R, Knudtson MD, Lee KE, Gangnon R, Klein BE. The Wisconsin Epidemiologic Study of Diabetic Retinopathy XXII: the twenty-five-year progression of retinopathy in persons with type I diabetes. Ophthalmology 2008; | I5:1859-68. [CrossRef]

4. Romney JS, Lewanczuk RZ. Vascular compliance is reduced in the early stages of type I diabetes. Diabetes Care 200I;24:2102-6.

5. Chiarelli F, Spagnoli A, Basciani F, Tumini S, Mezzetti A, Cipollone $F$, et al. Vascular endothelial growth factor (VEGF) in children, adolescents and young adults with type I diabetes mellitus: relation to glycaemic control and microvascular complications. Diabet Med 2000; 17:650-6. [CrossRef]

6. Nguyen NX, Kuchle M, Naumann GO. Quantification of blood-aqueous barrier breakdown after phacoemulsification in Fuchs' heterochromic uveitis. Ophthalmologica 2005;2 I 9:2I-5.

7. Dimitrova G, Kato S, Tamaki Y, Yamashita H, Nagahara M, Sakurai M, et al. Choroidal circulation in diabetic patients. Eye (Lond) 200I;15:602-7.[CrossRef]

8. Lockhart CJ, McCann A, Agnew CA, Hamilton PK, Quinn CE, McClenaghan $\mathrm{V}$, et al. Impaired microvascular properties in uncomplicated type I diabetes identified by Doppler ultrasound of the ocular circulation. Diab Vasc Dis Res 201 I;8:2 I I-20. [CrossRef]

9. Kawagishi T, Nishizawa Y, Emoto M, Konishi T, Maekawa K, Hagiwara $S$, et al. Impaired retinal artery blood flow in IDDM patients before clinical manifestations of diabetic retinopathy. Diabetes Care 1995; 18:1544-9. [CrossRef]

10. Arai T, Numata K, Tanaka K, Kiba T, Kawasaki S, Saito T, et al. Ocular arterial flow hemodynamics in patients with diabetes mellitus. J Ultrasound Med 1998; 17:675-8I. [CrossRef]

II. Yilmaz Ovali G, Ersoy B, Tuncyurek O, Urk V, Ozkol M, Ozhan $B$, et al. Doppler ultrasonography imaging of hemodynamic alteration of retrobulbar circulation in type I diabetic children and adolescents without retinopathy. Diabetes Res Clin Pract 2008;79:243-8. [CrossRef]

12. Halfter W, Moes S, Asgeirsson DO, Halfter K, Oertle P, Melo Herraiz E, et al. Diabetes-related changes in the protein composition and the biomechanical properties of human retinal vascular basement membranes. PLoS One 2017; I2:e0 I89857.[CrossRef]

13. Beltramo E, Porta M. Pericyte loss in diabetic retinopathy: mechanisms and consequences. Curr Med Chem 2013;20:3218-25.

14. Gil Hernández MA, Abreu Reyes P, Quintero M, Ayala E. Doppler ultrasound in type I diabetes: preliminary results. [Article in Spanish] Arch Soc Esp Oftalmol 200I;76:175-80.

15. Groh MJ, Michelson G, Langhans MJ, Harazny J. Influence of age on retinal and optic nerve head blood circulation. Ophthalmology 1996; 103:529-34. [CrossRef]

16. Williamson TH, Lowe GD, Baxter GM. Influence of age, systemic blood pressure, smoking, and blood viscosity on orbital blood velocities. Br J Ophthalmol 1995;79: I7-22. [CrossRef]

17. Peña AS, Liew G, Anderson J, Giles LC, Gent R, Wong TY, et al. Early atherosclerosis is associated with retinal microvascular changes in adolescents with type I diabetes. Pediatr Diabetes 2018; 19:1467-70. [CrossRef]

18. Järvisalo MJ, Putto-Laurila A, Jartti L, Lehtimäki T, Solakivi T, Rönnemaa $T$, et al. Carotid artery intima-media thickness in children with type I diabetes. Diabetes 2002;51:493-8. [CrossRef]

19. Chawla A, Chawla R, Jaggi S. Microvascular and macrovascular complications in diabetes mellitus: Distinct or continuum. Indian J Endocrinol Metab 2016;20:546-5I. [CrossRef]

20. Rosenson RS, Fioretto P, Dodson PM. Does microvascular disease predict macrovascular events in type 2 diabetes?. Atherosclerosis 2011;218:13-8. [CrossRef]

2I. Juutilainen A, Lehto S, Rönnemaa T, Pyörälä K, Laakso M. Retinopathy predicts cardiovascular mortality in type 2 diabetic men and women. Diabetes Care 2007;30:292-9. [CrossRef]

22. Ino-ue M, Azumi A, Yamamoto M. Ophthalmic artery blood flow velocity changes in diabetic patients as a manifestation of macroangiopathy. Acta Ophthalmol Scand 2000;78: 173-6. [CrossRef]

23. Writing Team for the Diabetes Control and Complications Trial/Epidemiology of Diabetes Interventions and Complications Research Group. Effect of intensive therapy on the microvascular complications of type I diabetes mellitus. JAMA 2002;287:2563-9. [CrossRef]

24. Group DCaCTR. The relationship of glycemic exposure ( $\mathrm{HbAlc})$ to the risk of development and progression of retinopathy in the diabetes control and complications trial. Diabetes 1995;44:968-83. [CrossRef]

25. Nathan DM; DCCT/EDIC Research Group. The diabetes control and complications trial/epidemiology of diabetes interventions and complications study at 30 years: overview. Diabetes Care 2014;37:9-16.[CrossRef]

26. Kawaguchi T, Mochizuki M, Miyata K, Miyata N. Phacoemulsification cataract extraction and intraocular lens implantation in patients with uveitis. J Cataract Refract Surg 2007;33:305-9. [CrossRef]

27. Juul A, Bang P, Hertel NT, Main K, Dalgaard P, Jørgensen K, et al. Serum insulin-like growth factor-I in 1030 healthy children, adolescents, and adults: relation to age, sex, stage of puberty, testicular size, and body mass index. J Clin Endocrinol Metab 1994;78:744-52. [CrossRef]

28. Berk BC. Vascular smooth muscle growth: autocrine growth mechanisms. Physiol Rev 2001;81:999-1030. [CrossRef]

29. Rodriguez-Fontal M, Kerrison JB, Alfaro DV, Jablon EP. Metabolic control and diabetic retinopathy. Curr Diabetes Rev 2009;5:3-7. [CrossRef]

30. Chantelau E. Evidence that upregulation of serum IGF-I concentration can trigger acceleration of diabetic retinopathy. $\mathrm{Br}$ J Ophthalmol 1998;82:725-30. [CrossRef] 